\title{
'The trees and grass and river and myself': Vida Lahey and Madge Roe as cultural subjects
}

\author{
Sue Lovell \\ s.lovell@griffith.edu.au.
}

\begin{abstract}
Madge Roe was a Brisbane-based illustrator who specialised in Australian flora and fauna. She captured the everyday in sketches and line illustrations to share with family and friends, and donated her time and talents to public causes. Although an avid supporter of and participant in Brisbane cultural groups, she was not a leading artist. Vida Lahey, however, was highly respected nationally and developing an international reputation. Both artists were embedded in family networks that sustained and promoted their well-being; both engaged with Brisbane culture, though in very different ways. In this paper, I argue for thinking holistically about culture and place as they are engaged by meaningmaking 'subjects'. Through Lahey's painting, Memoriam to Madge Roe, Roe's death notice and family sources, I focus on the articulation by subjects of geocultural meanings. By using this term, I indicate that meaning making is closely tied to place, to transitions between places and to the family as a form of subject 'placement'.
\end{abstract}

In The Idea of Culture, Terry Eagleton (2000: 1) notes that the term 'culture' is second only to its companion term, 'nature', in terms of its complexity. The International Encyclopaedia of the Social Sciences calls this complexity a 'notorious' state of affairs and resorts to etymology to link the word to 'various domains of life' (Darity 2008: 202). Following Raymond Williams, these domains include the cultivation that occurs through agricultural activity, the shift from nomadic life to a settled and therefore more productive domesticity, and the more civilised activities implied through the honouring of a deity and a capacity to protect community members. As civilisation develops, 'The primary meaning of cultivation, in cultura, has nevertheless been retained within the integrity of the word. Hence culture and cultura still echo the original main meaning of cultivation' (2008: 202). The understanding of culture per se thus remains strongly focused on tangible cultural production of particular types (primarily the visual and performing arts and literature) that takes place in particular - usually urbanised - places. It is still characterised, in other words, by Matthew Arnold's (2006: 11) criteria of 'sweetness and light', by the practice of 'beauty and intelligence' applied to the 'pursuit of perfection'. 
The emergent discipline of cultural geography has, however, challenged any implicit tendency to regard the 'cultivation' of Arnoldian values as central to culture, suggesting that:

Culture is not only high cultural practices like opera and theatre, nor is it confined to popular cultural activities like shopping, nor does it only materialise visually and artistically. Culture is also [...] the stories, interpretations or webs of meaning through which subjects make sense of themselves, others and their surroundings. (Dowling 1997: 24)

The operative phrases here are 'not only', 'nor is it', 'nor does it' and the broadly categorised 'subjects', displacing the narrower, elite category of cultural producers. Such phrases retain the significance of high and popular culture, of the visual and literary, but (again calling on Williams) allow room for the rich dimension of daily meaning-making in areas where, if culture is to be found, it is in the processes through which everyone tries to 'make sense' or interpret what is worthwhile in life.

In this article, I make an argument for thinking more holistically about culture and place as they are engaged by meaning-making 'subjects'. My discussion centres on the work of the now almost forgotten illustrator, Madge Roe, and her friend, the celebrated artist Vida Lahey. Only one of my sources, Vida Lahey's painting Memoriam for Madge Roe (1938), may be said to 'count' as culture in the narrower sense - though the very labelling of the art as memorial extends its value beyond that of the socio-cultural into something personal, more embedded in the familial. My other sources - Madge Roe's death notice, and manuscripts, artwork and stories from the Roe family archive - are the result of cultural practices by 'subjects' in the broader sense. The family is central to this process in two ways. In the first instance, family members like Madge make ad hoc 'products' and present them to a gentle audience as part of the process of communal meaning-making. In the second instance, later generations actively preserve those artefacts for the future. Such culture owes its very existence to specific familial networks and players engaging both family-based values and broader social values that express ideas about living worthy lives. Through Memoriam, the death notice and these family sources around which oral and written stories have now been woven, I tune in to the articulation by subjects of geo-cultural meanings. By this term, I indicate that meaning-making is closely tied to place, to transitions between places and to the family as a form of subject 'placement'. I trace the ways in which Madge Roe and her family brought the 'outdoors' - with its associations of physical well-being into the city or the home, and exported formal culture into the peripheries of island and farm. I emphasise the back and forth movement between Brisbane and places that have been special to the Roe family - one for about 130 years, the other for a much shorter time. The meanings that attach to both places emerge as subject driven, process-oriented counter-balances to culture as the 'cultivation' of an urban product.

Madge Roe died, aged 47, on 11 February 1938, and was cremated privately 'later in the day'. The Courier-Mail's death notice dedicated only 61 of its 156 words to Madge herself. The remaining space located her within her cultural and familial setting. Part of the notice reads: 
Miss Roe's artistic talent was widely recognised, and found expression in illustrating and designing, much of her work being based on native flora and fauna. She was a member of the Arts and Crafts Society and a lover of music and the arts generally. (Courier-Mail 1938)

Madge Roe was not a professional illustrator or artist (Lovell 2015), but she loved to capture everyday life in sketches and line illustrations to share with family and friends, as well as to donate her time and talents to public causes. ${ }^{1}$ It was through these public avenues of 'expression' that she was recognised within her cultural milieu. Roe was a visible presence at many public events. She was a subscriber to the Brisbane Art Fund, founded by Lahey and Daphne Mayo to supply the Art Gallery with important, contemporary art. Consequently, she was a guest at the private opening of the exhibition of paintings from the southern states (Brisbane Courier, 22 July 1930: 18), along with Brisbane's cultural and political elite, including Governor Sir John Goodwin. When the Lyceum Club hosted artist Jessie Traill as a guest of honour, both Roe and Lahey were there to see her presented with a 'posy of pink roses' and to hear the Lyceum President describe 'Brisbane's increasing interest in art, which she said was now being recognised beyond the State' (Brisbane Courier, 15 April, 1929: 15). Madge was present, too, at the opening of Vida's solo exhibitions (Courier-Mail, 21 May 1936: 21).

Madge also supported the performing arts. In 1921, she was among the crowd when the local Shakespeare Society held an event at the Albert Hall, 'which proved too small for the very large number of members and friends who attended' (Brisbane Courier, 12 May 1921). And she attended the final performance of the Russian Ballet at Her Majesty's Theatre. The '[p]rincipal dancers', wrote the Courier Mail's reporter, 'were recalled again and again, the supporting ballets were received with sustained applause which sometimes held up the action', and at the end of the performance 'streamers thrown from the auditorium to the stage formed a coloured maze above the orchestra, and the dancers had to take several curtain calls' (Courier-Mail, 24 October 1934: 19). Following this success, the company tour continued in Melbourne.

Madge's interest in art, and her willingness to volunteer her time, meant that she became one of three judges for an art exhibition of 400 entries conducted as part of the combined Brownies, Girl Guides, Cubs and Boy Scouts Fete in Government House gardens (Sunday Mail, 7 April 1935: 17). Although, like many women of her generation, she never married, Madge found ways to enjoy the company of young people. Other volunteer work included the design of the border of interwoven Flanders poppies in the Brisbane Boys' Grammar School Golden Book. This four-volume publication commemorated the 1020 Old Boys who served in World War I (Brisbane Grammar School 2015), In volume three, four of the first five entries list members of Vida Lahey's family.

Miss Roe was also Secretary of the Queensland Soldiers' Comforts Fund. When the fund compiled its war service rolls in 1919, Madge illustrated and hand-printed each page, representing the Comfort Fund details for various battalions and regiments, the Queensland Soldiers' Sock Fund, the Engineers and Miners Fund and any other group involved in the war. There were various decorative scrolls and borders; ornate, red initials were drawn at the beginning of each entry; and the relevant battalion insignia were placed at the head of each page. Additionally, there 
were a few line drawings, such as a dove with an olive branch (p. 13), and a peacetime triptych of a 'Sunday' drive along a tree lined avenue (p. 28) that clearly evoke the memorial avenues being planted at the time. Most poignantly, however, there is a view of an anonymous young woman with her back to the viewer, patiently gazing across the water into a distant sunrise or sunset reminiscent of the ANZAC badge. All is flanked by trees and underpinned with luxurious growth representing, perhaps, fertility and renewal. Where the ANZAC badge has an imperial crown in the centre, however, Madge has placed a small, dark sail. This motif reappears in Lahey's Memoriam, and can direct us to quite different elements of Madge Roe's character.

Memoriam for Madge Roe (1938), a watercolour over pencil $(62.8 \mathrm{~cm}$ x $58 \mathrm{~cm})$, was commissioned by the Roe family after Madge's death (MacAulay 1989: 78, 106) (Figure 1). It exists as a memorial in addition to the painting Art and Nature (1934) that Lahey executed independently of the Roe family. Art and Nature was purchased by the Queensland Art Fund and donated to the Art Gallery as its own memorial to Madge Roe (Queensland Art Gallery 2015) For an analysis of this painting, see Lovell (2014). Lahey was a professional artist, well known locally, interstate and overseas. She was deeply involved in the Brisbane art scene, and intent upon bringing the benefits of art to all levels of society, particularly children. With Daphne Mayo, Lahey was instrumental in gaining the support of America's Carnegie Foundation, agitating for better Art Gallery conditions and acquisitions and for exposing Queensland artists to progressive overseas developments in art (Lovell 2010). Memoriam features elements in Lahey's art with which she was increasingly associated: vibrant colour, native flora and, for those who knew her, an inclination to deeply personalise her art through representing objects that were symbolically relevant to an often personal audience (Lovell 2009).

On the right side of a cloth-covered table in the foreground of Memoriam, Lahey has placed an ink well and a stylus to represent the line drawings through which Madge expressed so much of what mattered to her. These familiar tools are dark, sharply outlined, but balanced by a dusky corner, at the top left. The solidity of stylus and inkpot intensifies the light that dances on the surface of gently rippled, pale-blue water visible through the window immediately behind. There are two boats: in the distance where the horizon divides the sea from an even paler sky is a small, white triangular sail. It cuts across the horizon, but is also held, framed by scrubby tree branches with yellow blossoms, hanging outside the window. The second craft is a rowing boat with a protruding oar, loosely moored on a triangle of the beach; this is balanced by yet another triangle formed by the line of the window sill. Because the top of the window sill is a paler version of the wall, but a darker version of the beach; the sill feature could easily pass as the shadow of the building in which the window is set. Because the outside branches are encroaching, the boundary between inner and outer space becomes less definitive, appropriately generating the questions: What is 'here' and what is 'beyond'? Where is Madge Roe?

In order to be a memoriam to Madge, the composite images in the painting have to provoke memories that are relevant to her and those who knew her. Turning now to the remaining 61 words that speak about Madge rather than her social position, it becomes possible to better recognise the significance of the components of Lahey's painting. There is a reiteration of Madge's love of young people, but we 


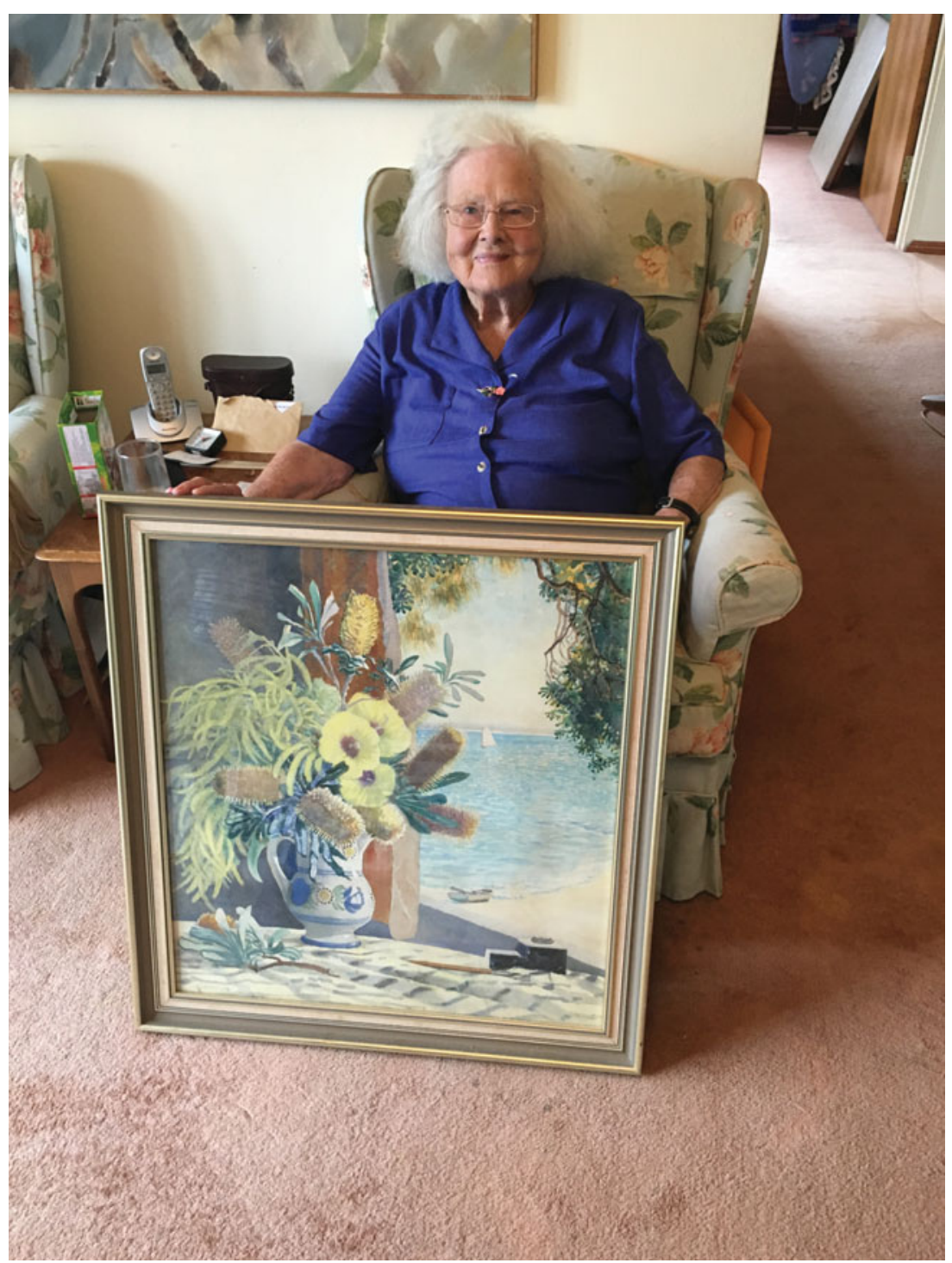

Figure 1

(Colour online) Judith Carson (nee Roe) with Vida Lahey's painting. Printed with permission of Judith Carson and Don Russell.

also discover why Lahey's Memoriam sets the stylus and inkpot against a coastal backdrop and incorporates a sail in much the same way as Madge's emblem in the Soldiers' Comfort Fund:

With her sister Miss Madge Roe delighted in entertaining friends, especially young people and children at the home on Stradbroke Island known as 'Roe's camp' [sic.], and established originally by her father when he was head master of the Brisbane Boys' Grammar School. One of her brothers is Dr Stanley Roe. Another, 
who has a property in the Texas district, married Miss Joan Robertson, daughter of Dr. and Mrs. W. N. Robertson. (Courier-Mail 1938)

From a professional family of educators and medicos, Roe belonged to what the daughter of two doctors, Mooloolaba-born actor Diane Cilento (1933-2011), has called 'a sort of aristocracy of Brisbane' (Cilento et al. 1994: 2). Oxford educated, Reginald Heber Roe was headmaster of Brisbane Grammar School (1876-1909), the leading school for sons of the upwardly mobile and elite. In 1909, he became an Inspector-General of Schools, later a Chief Advisor to the Minister and the first Vice Chancellor of Queensland University 1910-16 (Bryan 1966: 171), as well as a 'confidant' of twice Premier of Queensland and Chief Justice, Sir Samuel Griffith (Clarke 1988). Roe and Griffith had deep commitments to education, with Griffith sitting on the board of Brisbane Boys Grammar School (Joyce 1983) and both men working towards the establishment of Queensland University. While Griffith shaped citizens and citizenship through support for Federation, the drafting of the Constitution and reforms in criminal law and politics, Roe pursued a similar agenda through education.

One element of education avidly pursued by Roe was facilitated by his own passion for outdoor physical activity. In this respect, Stradbroke Island in Moreton Bay came to play a central role in the formation of a different type of culture that nevertheless retained a familial focus - albeit an extended one. Stradbroke Island initially was visited by the young Reggie Roe (1850-1926) and two friends, W. D. Box, a bank manager, and the much older Captain Claudius Whish (1827-90), whose daughter Maud became Mrs Reginald Roe in 1879. The friends enjoyed the island so much that in 1882 they bought adjoining blocks and camped under canvas at what was known as WHIROBO, an acronym of their names. (C. Roe 1991: 4) As headmaster of Brisbane Grammar, Roe — or 'The Skipper' as he came to be known, saw the potential of this retreat to offer personal development for his students. He regularly confronted the problem of what to do with his boarders over short holidays when they could not return to distant homes. As an educationalist, he was committed to a pedagogy that fostered 'social reform, upward social mobility and the moral, intellectual and physical development of each student' (Clarke 1988). The island provided the perfect venue for 'an early Australian experiment in adventure training' (Thearle et al. 1986: 432). In 1885, the first permanent galvanised iron hut in the 'adventure' camp replaced the tents used by the families. As the size of the group expanded to forty and more, 'the maids from the School House' were taken along to assist in caring for the visitors. Charles Roe, 'The Skipper's' grandson and Madge's eldest nephew, recalls days when:

The boys roamed the scrub, fished, sailed, swam in the ocean and in the calm Broadwater, and sat down to huge meals at the long trestle tables ... As many as forty-five people, adults, children, schoolboys, enjoyed the simple life - fishing, shooting, bathing, sailing, rowing and canoeing. Harpooning sting-rays, shovel nose sharks and saw fish on a wide sandbank in the middle of the Broadwater was an unusual and extremely popular pastime - the fun was fast and furious, particularly when the quarry swam directly at the line of hunters, and harpoons flew through the air from all directions. (Roe, C. [Jnr] 1991: 6) 
Such activities were not normalised as part of school curricula at this time, even in elite schools - although in New South Wales, school-related camping is now recognised as the 'precursor to outdoor education from 1890 to the 1960s' (Georgakis and Light 2010: 9). In South Australia, it is loosely acknowledged as existing 'since the dawn of time' and 'for at least the last fifty years', placing its inception a decade later (Pickett and Polley 2001: 50). Headmaster Roe seems to have wanted to introduce physical culture not simply because it suited him to be on Stradbroke at Easter - although no doubt it did - but because he had a commitment to building certain values. Governor Matthew Nathan acknowledged Roe's 'stress on character and physique, endeavouring to make every boy feel pride in his physical development and in generalised, rather than specialised, mental culture' (Thearle et al. 1986: 434).

What was known as 'muscular Christianity' (Brown 1987) and 'rational recreation' (Bailey 1978; Lawson 1973) were both popular environment-oriented movements in Australia in the later nineteenth and early twentieth centuries. Physical activities in the open air were considered healthy for mind, body and character. Roe's comments in his 1912 report to the Department of Public Instruction reveal a close link between physical culture and the production of virtuous citizens for the new nation:

Voluntary associations for sports, for mental and moral improvement, for philanthropy, for industry and commerce, all give incidentally a valuable training in self-denial, subordination, co-operation, and other civic virtues ... Character is even more important than knowledge for a people's welfare; and if the school systems of a State are to bear their full fruit they must not only be supported by the sympathy of parents and Legislature, but supplemented unceasingly by the co-operation of all these nonscholastic forces which play so important a part in the development of national character.

Physical 'nonscholastic forces' and formal culture were mutually imbricated rather than separate. The venues of the Brisbane Literary Circle, of which Roe was once president, also demonstrate a commitment to both. Indoor meetings were held in the Brisbane School of Arts, but every second meeting was outside. The group would:

board the government steamer and cruise to a designated spot along the Brisbane River. They gathered for general business, followed by literary entertainment and refreshments. On the boat ride back, an impromptu concert would often take place. This sort of activity advanced the belief in the outdoor surroundings as a means of promoting a healthy mind, body and soul, which contrasted with the notion of the 'disease' of popular fiction. (Day 2007: 399)

Lahey's representation of a sailing boat and a rowing boat in her Memoriam painting can be read as evidence of a strong association at Roe's Kamp of water activities as both rational recreation and a means of transportation.

As a peripheral location for outdoor cultural practices inclined towards the physical, Roe's Kamp (then opposite Southport's Grand Hotel) was much more remote than South Stradbroke seems today. There were several options for reaching the Kamp, depending on gender, age and ability: men could ride from Brisbane along the coach road via Beenleigh to Southport, while 'ladies' would take a coastal 
steamer. They would meet at Southport and be rowed, or row themselves, across the Broadwater. Several trips were often needed to transport provisions and people. As numbers increased, provisions were bought wholesale and delivered to the island by a trading vessel, the Regina (C. Roe 1991: 4, 16). Sometimes, the men would travel under 'The Skipper's' command, 'from Brisbane in wooden row boats that had six oars and a lug sail', camping 'on the islands in the Bay on the way down'; or the women would take the train 'to Southport, a wagon to the Grand Hotel and [go] across the Broadwater in one of the wooden row boats' (M. Roe 1988: 1).

It was, in fact, Madge who taught her nephew Charles to sail (C. Roe 1991: 8 ) in 'her 14 foot sharpie', the Maggie Kate (p. 22); Jean Hardie, a regular Kamp visitor, adds that the Maggie Kate had a jib and mainsail and that 'Madge, of course, always took the tiller and main sheet' (Hardie 1969: 2). Charles also writes about Madge importing 'a "Folbot" folding canoe made of rubber stretched over a timber frame' (1991: 41). Madge and sister Mollie would dress in 'sailor type blouses, bloomers and long stockings and sand shoes until the nineteen twenties, when they began to appear in long slacks, and Madge, greatly daring, even in a pair of shorts' (1991: 18).

Although the literature on muscular Christianity, rational recreation or outdoor education tends to focus on males, it is quite clear that the members of Reginald Roe's family were thoroughly egalitarian in the great outdoors. In the 1920s, Madge Roe wrote an account of her role on the family 'Pharm' [sic.] between 1910 and 1917. The Pharm was a 'broad tongue of land bounded on the North by the Pullen Pullen Creek and on the East and South by the Brisbane River' (C. Roe 1991). This places it slightly to the north-east of present Bellbowrie, about 22 kilometres from central Brisbane. Again, access to this periphery was difficult, a four-hour one-way trip (M. Roe. c 1920: 79). In Madge's consistently droll style, Pharming describes travelling to the closest railway station:

Going in from the Pharm, one would, in one's best - no, second-best-clean clothes - be required to step into and sit in a dank and muddy boat, row across the river, and climb out onto a hopelessly muddy and cattle-trampled bank, or risk a fall with even less desirable results on a slimy log. Next one crept up an almost perpendicular sandy cliff by means of a deeply cut cattle-track which rubbed all the remaining shine off the side of one's shoes, and left its mark on skirts or trousers, as the case might be. There followed a 3-mile walk, the first mile along a very sketchy track, the last along a bush road where one might be, but generally was not, picked up by a kindly cream-cart dragged along laboriously by a crippled horse. Coming home was even less attractive, as it was generally almost dark if not actually the middle of the night. (M. Roe c 1920: 83)

Unsurprisingly, as with Roe's Kamp, the many visitors came for a weekend or 'for a week or two' (M. Roe c. 1920: 82) sharing farm life to the full because 'it was inconceivable to our minds that the type of strenuous, and sometimes dangerous action which was the breath of life to us, might not be a pleasure to them' (c. 1920: 11). Overall, Madge's account demonstrates the Roe family's egalitarian attitudes in relation to life outdoors. She did fencing (c. 1920: 20), rounded up cattle (c. 1920: 28, 50), clipped, groomed and 'doctored' livestock (c. 1920: 29, 65, 67), dug up roots (c. 1920: 36), rode bareback, wore her shorts (c. 1920: 39, 106), swam naked (c. 1920: 40, 96), hunted (c. 1920: 43), moved bee hives (c. 1920: 58-9), milked 
cows summer and winter (c. 1920: 61), made hay (c. 1920: 62), harvested corn and potatoes (c. 1920: 63-4), fought fires (c. 1920: 85, 90-1), rowed (c. 1920: 106) and planted crops (c. 1920: 107). This is a far cry from the 'dainty girl, daughter of Mr and Mrs Reginald Roe' (Queensland Figaro, 21 April 1910: 3) who was a debutante at the Brisbane Rowing Club Ball.

Madge's account is also strewn with line drawings that she did on the farm, and more that Charles added from her sketchbooks when he transcribed the original in 1991. The blurring of the distinction between culture as city-based product and as something less formal and familial, and between inner and outer space in Memoriam, becomes even more meaningful as Madge gives her account of her favourite places. The old barn, for example, 'was a beautiful place, far more worshipful than the little church could ever have been' (c. 1920: 6), but she also felt that:

The nicest part of the house and the place we lived in whenever work and weather permitted, was the lower verandah, a wide open place with a cement floor level with the lawn of Mollie's garden. Here were easy chairs and a hammock and a big round table for long lingering morning and afternoon teas, and you looked straight out across grass and beds of flowers to the river and the trees of the opposite bank. (c. 1920: 5)

Although not technically a verandah, this structure clearly shares that function, and part of that function is more than the simply utilitarian provision of shade. Phillip Drew (1995: 147) writes:

Nothing quite expresses the relationship of Australians to their country so well as the veranda [sic]. This shelter simultaneously separates and links a building to landscape by imposing an open interval between the man-made object and nature.

The outside is drawn closer and the inside space rendered more congenial and sociable for the exchange of stories that make 'sense' of the world. This is an example of the role that played by an intimate and familial space in the formation of culture as a process of personal meaning-making. It is in the 'lingering' exchanges, in those moments of deeply felt well-being when place and people meet, that ideas are explored and exchanged. This was a leisurely, familial dynamic Roe carried forward into later creative moments. Family served as both the impetus and, often, the destination for the products of Roe's processing. In turn, the products became yet another way of relating, sharing values and forming attachments to place, to events and to more formal expressions of culture that were circulating.

Nothing demonstrates this as much as the response of Madge and her brother (Arthur) Stanley Roe to an Adam Lindsay Gordon poem. In 'A Dedication', the first verse captures an alienation from place, rather than an attachment to it:

They are rhymes rudely strung with intent less

Of sound than of words,

In lands where bright blossoms are scentless,

And songless bright birds;

Where, with fire and fierce drought on her tresses,

Insatiable Summer oppresses

Sere woodlands and sad wildernesses

And faint flocks and herds. (in Murdoch 1918) 
Stanley and Madge clearly disagreed with the poet. Madge illustrated a ten-page, rhymed, 'back-answer' written by her brother (Carson, in Lovell 2016). The names of flora and fauna were missing, but in place of each blossom or bird, Madge inserted a numbered pen and ink drawing. These were matched to the answers in an index. The pen and ink booklet, called $A$ Back-Answer, was printed off and Madge Roe closely supervised gatherings of friends and family to hand-colour the booklet (Lovell 2015). This is a clear example of a cultural response by 'subjects' to a cultural production of a very popular poet. It is not difficult to imagine the conversations about Gordon's diction and view among those having their morning or afternoon tea on the verandah overlooking the river. The combined Roe response brings the flora and fauna into the familial space and positions it alongside the sense of belonging experienced in the home, on the verandah, on the lawn, in order to defend its value and relevance to life. The booklet was not a commercial success. Nevertheless, copies of pen and ink originals and coloured versions remain prized possessions of the Roe family: the past process of making meaning remains within the circle of the family and continues to contribute to its historical sense of itself as the stories about this event are passed on.

Returning to Roe's Kamp, it is possible in a similar way to trace how formal intellectual 'city' culture was incorporated into the Kamp structure, just as the outdoors was incorporated into the house at the farm, the outside and the inside explored alongside one another in the Brisbane Literary Circle and the significance of the view through a window comes to play a role in Memoriam. A Kamp visitor in the 1930s, Ralph Goldsmith, knew the 'disarming' Madge through the 'annual Lady Skippers races conducted by the Oxley Sailing Club', and remembers the Christmas holiday in 1935:

We learned about operas from Madge, or revelled in listening in the clear open air to the voices of Paul Robeson, Peter Dawson, Joseph Schmidt, the sea shanties of Stuart Robertson, the satire of Noel Coward (in C Roe 1991: 19-20).

Jean Hardie confirms that popular and 'high' culture often occupied a leisurely space. She mentions Kamp sessions listening to the gramophone and having 'Robeson's “Lazy Bones! Lying in the Sun” competing for popularity with Bach's adorable choral “Jesu. Joy of Man's Desiring” [and being] very intrigued with Gershwin's fascinating "Rhapsody in Blue" (Hardie 1969: 5). According to Hardie (1969: 2), Madge 'could do anything from breaking in a pony to painting a picture. She was much beloved by young and old'. In between the outdoor culture of sailing, swimming, surfing, fishing and walking, Madge found time to read, sketch and paint $(\mathrm{C}$. Roe 1991: 18, 26, 44).

In the public domain, Lahey's inkpot, stylus and marine craft signify all of this, as do the few lines in the death notice referring to Stradbroke. Whilst acting as a trigger for those 'in the know', both these sources gloss the richness of Madge's character. As if to compensate, or to make the statement more boldly about Madge's relationship to Stradbroke as a specifically Australian place, the left side of Lahey's painting is completely occupied by a jug of vibrant native flora. The wattle, coastal banksia and beautiful hibiscus blooms (found in abundance at Stradbroke Island) are all in various shades of yellow, but one banksia, its fading leaves showing their undersides, has fallen symbolically from the arrangement onto the tablecloth 
and functions as a counterbalance to the inkpot and stylus and as a reminder of mortality. The picture therefore becomes both memorial and memento mori.

To be reminded of the vibrancy of Roe's life, her connection to place and her ability to make meaning through cultural practices that have become almost invisible, it is necessary to search for results of Madge's work. These bring us close again to something that is intrinsically valuable - a deep appreciation of life itself by a woman taken, not in her prime perhaps, but certainly too soon. Near the end of Pharming, Madge recalls an 'almost mystical experience' (c. 1920: 106-7) she had rowing back across the river after dropping someone on the town side:

The tide was high, and the river was completely lovely. Looking down stream, it turned abruptly to the left against a high rocky bank, with deep, grey-blue shadows; and looking up, there was a long stretch of water ending with a cliff of red earth, which fell away from cleared paddocks as the river bent sharply in the opposite direction. Near at hand were tall white river gums standing out against the bush of the south bank; while on our gravelly shore there was a line of red bottle brush trees stunted and twisted by floods into intricate designs, and just coming into early bloom, with the pleasant grassy slopes of the paddock leading up to the farm buildings above and behind them.

But it was the still misty air that fascinated me. It was not the usual kind of mist which hangs more heavily in hollows, and is blown away. On this morning it was the quality of the whole air that was misty, and lent amazing beauty to all about me; while the foretelling of the heat to come gave an impression of immense power. The air was absolutely still; the water and earth and birds and creatures were still; and everything, the pale sky, the trees and grass and river and myself, seemed to be bound together by the strong warmth of this soft milky air.

Not only does this account rival any cultural 'product', it also reveals Madge's painterly eye for colour and form, and her sensitivity to surroundings. Shorn of the deliberate structuring of her narrative through humour and at times satire, there is a sense of reaching something that is an integral, spiritual part of Madge. It provides an opportunity to better understand the imagery in Memoriam, and to recognise the formal sterility of the death notice, with its focus on external social positioning that occludes rather than reveres a life.

\section{Endnote}

1 Thanks must go to Dorothy Steindl for her generosity in supporting the writing of this article through interview and liaison with family members.

\section{References}

Arnold M. 2006 [1869]. Culture and anarchy: An essay in social and political criticism. Oxford: Oxford University Press.

Bailey P. 1978, Leisure and class in Victorian England: Rational recreation and the contest for control 1830-1885. London: Routledge and Kegan Paul.

Brisbane Grammar School. 2015. 'About, Grammar History, Golden Book', https://www.brisbanegrammar.com/About/GrammarHistory/Pages/The-GoldenBook.aspx, accessed 6 April 2015. 
Brown D.W. 1987. 'Muscular Christianity in the Antipodes: Some observations on the diffusion and the emergence of a Victorian ideal in Australian social theory'. Sporting Traditions 3(2): 173-87.

Bryan H. 1966. 'The University of Queensland, 1910-1960: An essay towards a history'. Unpublished manuscript, Fryer Library, University of Queensland, St Lucia.

Cilento D., Atkinson S. and Maranta B.D. 1994. Queensland: Growing up - Authors' experiences of growing up in Queensland and their views on Queensland growing up'. Queensland Review 1(1): n.p.

Clarke E. 1988. 'Roe, Reginald Heber (1850-1926)'. In Australian Dictionary of Biography. Canberra: National Centre of Biography, Australian National University, http://adb.anu.edu.au/biography/roe-reginald-heber-8253/text14453, accessed 4 April 2015.

Courier-Mail 1938. 'Death notice, Madge Roe', 12 February: 15.

Darity William A. Jr (ed.). 2008. 'Culture', International Encyclopaedia of the Social Sciences, Vol. 2, $2^{\text {nd }}$ ed. New York: Macmillan.

Day L. 2007. 'The Brisbane Literary Circle: A strategy to elevate the communal mind. The Australian Library Journal, 56(3/4): 392-404. DOI: 10.1080/00049670.2007.10722431.

Dowling R. 1997. 'Planning for culture in urban Australia'. Australian Geographical Studies 35(1): 13-31.

Eagleton T. 2000, The Idea of Culture, Malden, MA: Blackwell.

Georgakis S. and Light R. 2010. 'The outdoor classroom: School camping as education in NSW 1890-1960s'. Australian Journal of Outdoor Education, 14(1): 3-12.

Hardie J. 1969. History of Hardie's Kamp on Stradbroke Island. Brisbane: Author.

Joyce R.B. 1983. 'Griffith, Sir Samuel Walker'. In Australian Dictionary of Biography, Canberra: National Centre of Biography, Australian National University.

Lahey S. 2003. The Laheys: Pioneers and sawmillers. Brisbane: Author.

Lawson R. 1973, Brisbane in the 1890s: A study of an Australian urban society. Brisbane: University of Queensland Press.

Lovell S. 2009, Interview with Shirley Lahey. Notes held by Sue Lovell.

Lovell S. 2010. 'Vida Lahey's progressive activism for children's art education'. Australian Historical Studies 41(3): 269-85.

Lovell S. 2014. 'Bats, books and biography: Searching for Vida Lahey', Queensland Review 21(1): 72-83.

Lovell S. 2015. Interview with Dorothy Steindl. Notes held by Sue Lovell.

Lovell S. 2016. Interview with Judith Carson. Notes held by Sue Lovell.

MacAulay B. 1989. Songs of colour: The art of Vida Lahey. Brisbane: Queensland Art Gallery.

Murdoch Sir W. 1918. The Oxford Book of Australian Verse. Oxford: Oxford University Press.

Pickett B. and Polley S. 2001. 'Investigating the history of outdoor education in South Australia'. Australian Journal of Outdoor Education, 5(2): 49-53.

Queensland Art Gallery. 2015. Transparent: Watercolours in Queensland 1850s-1980s. Travelling Exhibition, Gallery of Modern Art, Brisbane, http://www.qagoma.qld.gov.au/exhibitions/touring/transparentontour, accessed 7 April 2015. 
Queensland Soldiers' Comforts Fund Records 1920, OM73-29, John Oxley Library, State Library of Queensland, Brisbane.

Roe C. 1920. 'Foreword', in M. A. (Madge) Roe c. 1920, Pharming: Stories of life on a Brisbane River dairy farm in the years 1910 to 1917, by one of the farmers. Available from Dr C. Roe, 131 Kadumba St, Yeronga, Qld, 4104.

Roe C. [Jnr] 1991, A history of Roe's Kamp: South Stradbroke Island 1882-1991. Available from Dr C. Roe, PO Box 678 Runaway Bay, Qld, 4104.

Roe M.A. (Madge. c. 1920, Pharming: Stories of life on a Brisbane River dairy farm in the years 1910 to 1917, by one of the farmers. Available from Dr C Roe, PO Box 678 Runaway Bay, Qld, 4104.

Roe Marina. 1988. 'Roe's Kamp holidays'. Scribblers Papers, 1911-2004 Box 10528, John Oxley Library, Brisbane, 5746/165.

Roe R. 1912. Report to the Department of Public Instruction. Brisbane: Queensland Government.

Thearle J., Pearn J. and Roe C. 1986. 'Roe's Kamp: A pioneer experiment in secondary education', Journal of the Royal Historical Society of Queensland 12(6): 432-40. 